\title{
Effect of antidepressant drugs on the in-vitro egg- penetrating ability of golden hamster epididymal spermatozoa
}

\author{
D. M. Stein* and H. Schnieden \\ Department of Pharmacology, Materia Medica and Therapeutics, University of Manchester, \\ Stopford Building, Oxford Road, Manchester M13 9PT, U.K.
}

\begin{abstract}
Summary. Tricyclic antidepressants appeared to be without effect, except for desipramine which significantly decreased whiplash motility after spermatozoa were added to eggs, and clomipramine which decreased motility and whiplash motility in epididymal sperm suspensions after pretreatment of males. Mianserin and viloxazine were also without effect, but nomifensine significantly decreased sperm motility and whiplash motility and inhibited egg penetration almost completely. After $3 \mathrm{~h}$ preincubation with $0.75 \mathrm{mmol}$ nomifensine hydrogen maleate $/ 1,2 / 181$ and $0 / 256$ eggs were penetrated in two separate series of experiments. Control groups in these series gave medians of $90-100 \%$ penetration by $4 \cdot 5-5.5 \mathrm{~h}$ after spermatozoa and eggs were mixed. Maleic acid had a similar effect (1/253 eggs penetrated) whilst nomifensine hydrochloride was inactive, suggesting that the effect was due to the maleate moiety of the original nomifensine hydrogen maleate salt used.
\end{abstract}

\section{Introduction}

Psychotropic drugs can affect male reproduction (Beaumont, 1979; Millar, 1979; Schnieden, 1979; Barnes, Bamber \& Watson, 1979). Dibenzazepines such as amitryptyline and imipramine which are used as antidepressants have been shown to decrease human and rabbit sperm motility in vitro (Schnieden, 1974a, b; Levin, Amsterdam, Winokur \& Wein, 1981).

In-vitro fertilization has been used to test drug effects. Low concentrations of desmosteryl sulphate inhibited hamster egg penetration in vitro (Bleau, Vandenheuvel, Andersen \& Gwatkin, 1975). Pretreatment of males with $\alpha$-chlorohydrin has also been shown to inhibit subsequent penetration of rat and mouse (Tsunoda \& Chang, 1976) and hamster (Stein \& Schnieden, 1980) eggs in vitro. The penetration of mouse eggs in vitro is decreased by ethanol (Anderson, Reddy \& Zaneveld, 1980); this alcohol also inhibited hamster egg penetration by hamster or human spermatozoa (Cash \& Rogers, 1981). Spermatozoa from some patients treated with sulphasalazine for ulcerative colitis or Crohn's disease had a reduced ability to penetrate zona-free hamster eggs (Sessions, Fried, Blasco \& Hall, 1981).

In view of the reports cited above concerning the effect of psychotropic drugs on spermatozoa, this study was initiated to investigate the effect of a range of antidepressant compounds on the interaction of hamster spermatozoa and eggs in vitro. Some preliminary data on clomipramine have been reported (Stein \& Schnieden, 1980).

* Present address: Department of Human Biology, Chelsea College, Manresa Road, London SW3 6LX, U.K. 


\section{Materials and Methods}

Animals, drugs and medium

Golden hamsters (Mesocricetus auratus) were fed on a pellet diet with unlimited access to water. The animal room temperature was kept at about $24^{\circ} \mathrm{C}$, and was lit by artificial light from $05: 00$ to $19: 00 \mathrm{~h}$.

The medium used was a modified Tyrode's solution designated Tyrode-B2 (Bavister, 1971). It consisted of $(\mathrm{mmol} / \mathrm{l}): \mathrm{NaCl} 112 \cdot 40, \mathrm{KCl} 2 \cdot 20, \mathrm{CaCl}_{2} \cdot 6 \mathrm{H}_{2} \mathrm{O} 1 \cdot 48, \mathrm{NaH}_{2} \mathrm{PO}_{4} \cdot 2 \mathrm{H}_{2} \mathrm{O} 0 \cdot 29$, $\mathrm{MgCl}_{2} .6 \mathrm{H}_{2} \mathrm{O} 0 \cdot 41, \mathrm{NaHCO}_{3} 36 \cdot 08$, D-glucose $4 \cdot 56$, sodium pyruvate $0 \cdot 10$, bovine serum albumin (Fraction V, Sigma) $0.9 \%$, phenol red $0.002 \%$, benzyl penicillin sodium 100 i.u. $/ \mathrm{ml}$ and streptomycin sulphate $50 \mu \mathrm{g} / \mathrm{ml}$ (Glaxo). All reagents were analytical grade when possible and Analar water $(\mathrm{BDH})$ was used as diluent. The medium was sterilized by Millipore filtration $(0.22 \mu \mathrm{m})$, stored at $4^{\circ} \mathrm{C}$ and used when $1-4$ days old. Osmolality was routinely $292 \mathrm{mosmol} / \mathrm{kg}$ water as assessed by freezing-point depression (Advanced Osmometer).

Drugs were donated as follows: amitriptyline (Merck, Sharp and Dohme, Hoddesdon, Herts, U.K.); clomipramine, desmethylclomipramine, imipramine and desipramine (Ciba-Geigy, Horsham, West Sussex, U.K.); mianserin (Organon, Morden, Surrey, U.K.); nomifensine hydrogen maleate and hydrochloride (Hoechst, Hounslow, Middlesex, U.K.); nortriptyline (Lilly, Basingstoke, Hants, U.K.); and viloxazine (ICI, Alderley Park, Cheshire, U.K.). Small volumes of drug-containing medium were freshly prepared in two ways. For higher concentrations, the drug was dissolved directly in Tyrode-B2. For lower concentrations, a 100-times concentrated drug solution was prepared in Analar water and diluted appropriately with Tyrode-B2. The control medium was also similarly diluted with sterile Analar water. Drug-containing media were refiltered.

Medium was equilibrated with the gas-phase of the incubator (continuous-flow $5 \% \mathrm{CO}_{2}$ in air, $37^{\circ} \mathrm{C}$; Laboratory and Electrical Engineering Company) by preparing droplets under paraffin oil in tissue culture dishes ( $35 \mathrm{~mm}$, Falcon) and placing them in the incubator overnight before an experiment. The paraffin oil used was heavy grade from Boots (Nottingham, U.K.); it was used unsterilized after being shown to be free of bacterial contamination.

\section{Spermatozoa and eggs}

Using aseptic techniques, epididymal sperm suspensions were prepared by puncturing the cauda epididymidis of a male hamster (9-10 weeks old) in $200 \mu$ l of control or drug-containing medium. Epididymal sperm suspensions were incubated for $3 \mathrm{~h}$ before a small volume, nominally 1 $\mu$, was transferred to a freshly prepared egg-containing droplet. Spermatozoa were counted with a Model $Z_{B}$ Coulter Counter, set to previously ascertained counting parameters (Stein, 1979). The volume of sperm suspension transferred for 'insemination' was adjusted to give a sperm concentration in the fertilization droplet of about $0.5-5.0 \times 10^{6} / \mathrm{ml}$. This was checked by counting a 'mock' droplet $(40+10 \mu \mathrm{l})$ to which a similar volume of sperm suspension was transferred.

\section{Egg collection, insemination and examination}

Eggs were obtained by induction of superovulation in immature female hamsters, 5-6 weeks old (Yanagimachi \& Chang, 1964). Females were injected intraperitoneally with 30 i.u. PMSG (Sigma) followed 52-54 h later by 25 i.u. hCG (Sigma). Eggs were collected about $17 \mathrm{~h}$ later by puncturing the swollen part of the ampulla in $60 \mu \mathrm{l}$ Tyrode-B2 under oil. The cumulus cell mass containing eggs was transferred in a volume of $10 \mu \mathrm{l}$ to $40 \mu \mathrm{l}$ equilibrated medium under oil.

Sperm motility was assessed subjectively, routinely once per hour. The proportion of motile spermatozoa and the proportion of these showing whiplash motility (Yanagimachi, 1970) were judged to the nearest $10 \%$ by observation of the edge of the whole droplet of sperm suspension. 
(Hamster spermatozoa in a wet preparation between a slide and cover-slip showed decreased motility.) The proportion of acrosome-reacted motile spermatozoa was assessed by the criteria of Talbot \& Franklin (1976). Sufficient numbers of spermatozoa (at least 50) could usually be observed in the small droplet of medium used to examine eggs. Otherwise a wet preparation was made under a cover-slip supported on vaseline spots.

At various times after mixing with spermatozoa, eggs were examined using phase-contrast microscopy $(\times 500$, Zeiss $)$ immediately after mounting in a small volume of medium under a coverslip supported on four spots of vaseline. Carefully rolling the cover-slip enabled the entire egg surface to be examined (Austin \& Smiles, 1948). An egg was classed as penetrated if one or more spermatozoa were lying on/in the egg plasma membrane or in the egg cytoplasm. Usually, a decondensing sperm head or male pronucleus formation was seen (Austin, 1956). The presence of a sperm head was confirmed by the observation of a corresponding sperm tail.

All allocations of animals, gametes and treatments were made in a strictly random order using random number tables. The identity of the control or drug-containing media was 'blind' to the investigator. Non-parametric statistics were used to analyse the data. Egg penetration observations and sperm values, data which were compared between treatments and at different time periods, were analysed using the Kruskal-Wallis two-way analysis of variance (Scheirer, Ray \& Hare, 1976). The Null Hypothesis was that there was no difference between the groups and the significance level, $\alpha$, was 0.05 .

\section{Results}

The following compounds had no effect on the ability of hamster spermatozoa to penetrate eggs: clomipramine and amitryptyline at 0.0075 and $0.75 \mathrm{mmol} / 1$, and imipramine, nortriptyline, desipramine and desmethylclomipramine at $0.75 \mathrm{mmol} / \mathrm{l}$. Hamster sperm motility, including whiplash motility, and the occurrence of the acrosome reaction were likewise unaffected except for desipramine. This compound $(0.75 \mathrm{mmol} / \mathrm{l})$ significantly decreased whiplash motility after transfer to the egg-containing droplets $(P<0.01)$. Clomipramine was further investigated by pretreating male hamsters with $0.03 \mathrm{mmol} / \mathrm{kg}$ intraperitoneally daily for 10 days. During $8 \mathrm{~h}$ of observation (after obtaining epididymal spermatozoa on the 11 th day), sperm motility $(P<0.01)$ and whiplash motility $(P<0.05)$ were significantly reduced in the drug-treated animals. In the control group, median proportions of motile spermatozoa during incubation for $8 \mathrm{~h}$ were $80-90 \%$ with $70-80 \%$ of these showing whiplash motility after incubation for $3 \mathrm{~h}$, while spermatozoa from clomipramine treated males showed corresponding medians of $70-80 \%$ and $60-70 \%$. However, after transfer to the egg-containing droplets, sperm motility and whiplash motility, the occurrence of the acrosome reaction and egg penetration were similar in both groups.

Three series of experiments are reported in more detail. In each, one control group was compared to three drug groups (mianserin, nomifensine and viloxazine) in a completely randomized design. Hamster epididymal spermatozoa were incubated for $3 \mathrm{~h}$ with each of these compounds at $0.75 \mathrm{mmol} / \mathrm{l}$. Mianserin and viloxazine had no effect on any of the sperm values assessed. However, sperm motility, including whiplash motility, in the epididymal sperm suspensions was significantly decreased in the nomifensine group compared to control $(P<0 \cdot 001)$. Both characteristics had decreased to zero in the nomifensine group by $6 \mathrm{~h}$ when the control group still maintained a median of $60 \%$ motile spermatozoa (Table 1 ). After incubation with nomifensine for $3 \mathrm{~h}$ and transfer to the eggs, motility and whiplash motility were again significantly decreased compared to control $(P<0.001)$. In the controls medians of about $60 \%$ motile spermatozoa were seen throughout the incubation with eggs, and medians of $65-70 \%$ of these showed whiplash motility. In the nomifensine group, the respective figures were $35-40 \%$ and $45-50 \%$. But, like mianserin and viloxazine, nomifensine did not affect the occurrence of the acrosome reaction 
compared to control. By $2 \mathrm{~h}$ after mixing with eggs, a median $14 \%$ of motile spermatozoa were acrosome-reacted in the control group compared to $32 \%$ in the nomifensine group. By $5 \mathrm{~h}$ the medians were 100 and $90 \%$ respectively.

Table 1. Hamster epididymal sperm motility in vitro after incubation in control medium or that containing $0.75 \mathrm{mmol} / \mathrm{l}$ of the compounds indicated

\begin{tabular}{|c|c|c|c|c|c|c|c|c|c|}
\hline \multirow[b]{2}{*}{ Treatment } & \multicolumn{9}{|c|}{ Incubation period (h) } \\
\hline & 0 & 1 & 2 & 3 & 4 & 5 & 6 & 7 & 8 \\
\hline \multicolumn{10}{|l|}{ Motility } \\
\hline Control & $\begin{array}{c}90 \\
(80-90)\end{array}$ & $\begin{array}{c}90 \\
(80-90)\end{array}$ & $\begin{array}{c}90 \\
(80-90)\end{array}$ & $\begin{array}{c}80 \\
(70-80)\end{array}$ & $\begin{array}{c}70 \\
(60-80)\end{array}$ & $\begin{array}{c}70 \\
(50-70)\end{array}$ & $\begin{array}{c}60 \\
(50-70)\end{array}$ & $\begin{array}{c}60 \\
(50-60)\end{array}$ & $\begin{array}{c}55 \\
(40-60)\end{array}$ \\
\hline $\begin{array}{l}\text { Nomifensine } \\
\text { hydrogen } \\
\text { maleate }\end{array}$ & $\begin{array}{c}90 \\
(80-90)\end{array}$ & $\begin{array}{c}90 \\
(80-90)\end{array}$ & $\begin{array}{c}80 \\
(70-90)\end{array}$ & $\begin{array}{c}70 \\
(20-80)\end{array}$ & $\begin{array}{c}10 \\
(0-60)\end{array}$ & $\begin{array}{c}0 \\
(0-20)\end{array}$ & $\begin{array}{c}0 \\
(0-10)\end{array}$ & 0 & 0 \\
\hline $\begin{array}{l}\text { Nomifensine } \\
\text { hydrochloride }\end{array}$ & 90 & $\begin{array}{c}90 \\
(80-90)\end{array}$ & $\begin{array}{c}85 \\
(80-90)\end{array}$ & $\begin{array}{c}80 \\
(70-90)\end{array}$ & $\begin{array}{c}65 \\
(60-80)\end{array}$ & $\begin{array}{c}60 \\
(50-80)\end{array}$ & $\begin{array}{c}45 \\
(40-70)\end{array}$ & $\begin{array}{c}40 \\
(30-70)\end{array}$ & $\begin{array}{c}40 \\
(30-60)\end{array}$ \\
\hline Maleic acid & $\begin{array}{c}90 \\
(80-90)\end{array}$ & $\begin{array}{c}80 \\
(70-90)\end{array}$ & $\begin{array}{c}75 \\
(70-80)\end{array}$ & $\begin{array}{c}65 \\
(60-70)\end{array}$ & $\begin{array}{c}60 \\
(50-70)\end{array}$ & $\begin{array}{c}50 \\
(10-70)\end{array}$ & $\begin{array}{c}10 \\
(0-40)\end{array}$ & $\begin{array}{c}0 \\
(0-30)\end{array}$ & $\begin{array}{c}0 \\
(0-30)\end{array}$ \\
\hline \multicolumn{10}{|l|}{ Whiplash motility } \\
\hline Control & 0 & 0 & $\begin{array}{c}70 \\
(50-80)\end{array}$ & 70 & $\begin{array}{c}70 \\
(60-70)\end{array}$ & $\begin{array}{c}70 \\
(50-70)\end{array}$ & $\begin{array}{c}70 \\
(50-70)\end{array}$ & $\begin{array}{c}60 \\
(50-70)\end{array}$ & $\begin{array}{c}60 \\
(50-60)\end{array}$ \\
\hline $\begin{array}{l}\text { Nomifensine } \\
\text { hydrogen } \\
\text { maleate }\end{array}$ & 0 & 0 & $\begin{array}{c}70 \\
(60-70)\end{array}$ & $\begin{array}{c}70 \\
(40-70)\end{array}$ & $\begin{array}{c}5 \\
(0-70)\end{array}$ & $\begin{array}{c}0 \\
(0-50)\end{array}$ & 0 & 0 & 0 \\
\hline $\begin{array}{l}\text { Nomifensine } \\
\text { hydrochloride }\end{array}$ & 0 & 0 & $\begin{array}{c}70 \\
(60-70)\end{array}$ & 70 & 70 & $\begin{array}{c}65 \\
(50-70)\end{array}$ & $\begin{array}{c}55 \\
(50-70)\end{array}$ & $\begin{array}{c}50 \\
(40-70)\end{array}$ & $\begin{array}{c}40 \\
(40-60)\end{array}$ \\
\hline Maleic acid* & 0 & 0 & $\begin{array}{c}65 \\
(60-70)\end{array}$ & $\begin{array}{c}70 \\
(60-70)\end{array}$ & $\begin{array}{c}65 \\
(60-70)\end{array}$ & $\begin{array}{c}55 \\
(40-70)\end{array}$ & $\begin{array}{c}5 \\
(0-50)\end{array}$ & $\begin{array}{c}0 \\
(0-50)\end{array}$ & $\begin{array}{c}0 \\
(0-40)\end{array}$ \\
\hline
\end{tabular}

Values are median $\%$ scores (and range) for 6 observations per treatment.

* Significantly different from control values $(P<0.001)$.

Mianserin and viloxazine had no effect on egg penetration. However, after preincubation with nomifensine, subsequent egg penetration in vitro was vitually eliminated compared to control $(P<$ 0.001 , Table 2, Series 1). There were no significant differences between any of the groups when osmolality, $\mathrm{pH}$ and sperm concentration in the epididymal sperm suspension or in the fertilization droplets were compared.

The nomifensine salt that was investigated was the hydrogen maleate whereas all other salts previously had been hydrochlorides. In the second series of experiments, the effect of $0.75 \mathrm{mmol}$ nomifensine hydrogen maleate/ 1 was confirmed and shown to be concentration-dependent since $0.0075 \mathrm{mmol} / 1$ of this compound was without effect (Table 2, Series 2). In addition, preincubation with $0.75 \mathrm{mmol}$ maleic acid/l had a similar effect to the same concentration of nomifensine hydrogen maleate in that sperm motility and whiplash motility were significantly decreased compared to control $(P<0.01$ in the epididymal sperm suspensions, $P<0.001$ in the fertilization droplets). Whilst the occurrence of the acrosome reaction was not affected, egg penetration was significantly reduced by maleic acid, again virtually to zero $(P<0.001)$.

The hydrochloride salt of nomifensine was made available and tested: 0.0075 and $0.75 \mathrm{mmol}$ nomifensine hydrochloride/1 had no effect compared to control on sperm motility or whiplash motility in the epididymal sperm suspensions or in the fertilization droplets. Neither the acrosome reaction nor egg penetration were affected by either concentration of the compound. The effect of maleic acid was concentration-dependent since $0.0075 \mathrm{mmol} / 1$ had no effect on sperm characteristics or egg penetration in vitro (Table 2, Series 3). 
Table 2. The effect of various compounds on hamster epididymal spermatozoa incubated for $3 \mathrm{~h}$ and added to eggs in vitro

\begin{tabular}{|c|c|c|c|c|c|c|}
\hline \multirow[b]{2}{*}{ Treatment } & \multirow{2}{*}{$\begin{array}{l}\text { Conc. } \\
(\mathrm{mmol} / \mathrm{l})\end{array}$} & \multicolumn{4}{|c|}{ Incubation period with eggs (h) } & \multirow{2}{*}{$\begin{array}{l}\text { Total no. of } \\
\text { eggs } \\
\text { penetrated/ } \\
\text { no. examined }\end{array}$} \\
\hline & & 2.5 & $3 \cdot 5$ & $4 \cdot 5$ & $5 \cdot 5$ & \\
\hline \multicolumn{7}{|l|}{ Series $1^{*}$} \\
\hline Control & & $\begin{array}{c}0 \\
(0-13)\end{array}$ & $\begin{array}{c}63 \\
(17-100)\end{array}$ & $\begin{array}{c}90 \\
(60-100)\end{array}$ & $\begin{array}{c}100 * \\
(53-100)\end{array}$ & $152 / 232$ \\
\hline Mianserin $\mathrm{HCl}$ & 0.75 & $\begin{array}{c}0 \\
(0-9)\end{array}$ & $\begin{array}{c}55 \\
(0-100)\end{array}$ & $\begin{array}{c}100 \\
(67-100)\end{array}$ & $\begin{array}{c}100 \\
(81-100)\end{array}$ & $155 / 236$ \\
\hline $\begin{array}{l}\text { Nomifensine hydrogen } \\
\text { maleate }\end{array}$ & 0.75 & 0 & 0 & $\begin{array}{c}0 \\
(0-17)\end{array}$ & 0 & $2 / 181$ \\
\hline Viloxazine $\mathrm{HCl}$ & 0.75 & 0 & $\begin{array}{c}91 \\
(0-100)\end{array}$ & $\begin{array}{c}100 \\
(0-100)\end{array}$ & $\begin{array}{c}100 \\
(29-100)\end{array}$ & $167 / 225$ \\
\hline \multicolumn{7}{|l|}{ Series $2^{*}$} \\
\hline Control & & 0 & $\begin{array}{c}94 \\
(15-100)\end{array}$ & $\begin{array}{c}100 \\
(80-100)\end{array}$ & $\begin{array}{c}100 \dagger \\
(87-100)\end{array}$ & $202 / 274$ \\
\hline $\begin{array}{l}\text { Nomifensine hydrogen } \\
\text { maleate }\end{array}$ & 0.0075 & $\begin{array}{c}0 \\
(0-75)\end{array}$ & $\begin{array}{c}73 \\
(0-80)\end{array}$ & $\begin{array}{c}100 \\
(92-100)\end{array}$ & $\begin{array}{c}100 \\
(92-100)\end{array}$ & $142 / 197$ \\
\hline & 0.75 & 0 & 0 & 0 & 0 & $0 / 256$ \\
\hline Maleic acid & 0.75 & 0 & 0 & $\begin{array}{c}0 \\
(0-9)\end{array}$ & 0 & $1 / 253$ \\
\hline \multicolumn{7}{|l|}{ Series 3} \\
\hline Control & & $\begin{array}{c}0 \\
(0-17)\end{array}$ & $\begin{array}{c}84 \\
(75-100)\end{array}$ & $\begin{array}{c}100 \\
(92-100)\end{array}$ & $\begin{array}{c}100 \ddagger \\
(91-100)\end{array}$ & $242 / 308$ \\
\hline \multirow[t]{2}{*}{ Nomifensine $\mathrm{HCl}$} & 0.0075 & $\begin{array}{c}0 \\
(0-100)\end{array}$ & $\begin{array}{c}97 \\
(83-100)\end{array}$ & $\begin{array}{c}100 \\
(90-100)\end{array}$ & 100 & $278 / 323$ \\
\hline & $0 \cdot 75$ & $\begin{array}{c}0 \\
(0-20)\end{array}$ & $\begin{array}{c}82 \\
(40-100)\end{array}$ & $\begin{array}{c}100 \\
(92-100)\end{array}$ & 100 & $230 / 293$ \\
\hline Maleic acid & 0.0075 & $\begin{array}{c}6 \\
(0-58)\end{array}$ & $\begin{array}{c}89 \\
(67-96)\end{array}$ & $\begin{array}{c}100 \\
(94-100)\end{array}$ & $\begin{array}{c}100 \\
(94-100)\end{array}$ & $278 / 329$ \\
\hline
\end{tabular}

Values are median percentage (and range) for 6 observations per treatment.

* Significant difference between the treatments $(P<0.001)$.

$\dagger$ Significant difference between the time periods $(P<0.05)$.

$\ddagger$ Significant difference between the time periods $(P<0.001)$.

\section{Discussion}

In this study, a range of tricyclic antidepressant drugs had no effect on hamster epididymal sperm motility, the acrosome reaction or egg penetration in vitro after spermatozoa were incubated with the drug. For example, clomipramine, amitriptyline, imipramine and desmethylclomipramine and nortriptyline (their desmethylated derivatives) had no apparent effects on hamster spermatozoa at the concentrations tested. However, desipramine, the corresponding analogue of imipramine, did appear to decrease whiplash motility significantly after spermatozoa were added to eggs. Additionally, after pretreatment of male hamsters, clomipramine appeared to decrease significantly motility and whiplash motility in epididymal sperm suspensions. For neither drug, however, were the acrosome reaction or egg penetration affected compared to controls.

Other tricyclic antidepressants have been reported to decrease sperm motility. Human sperm motility was decreased after incubation with trimipramine although oral treatment of rats with this compound did not affect spermatozoa in the vas deferens (Kalla \& Bansal, 1973). Human sperm motility in vitro was also significantly decreased by amitriptyline and imipramine (Schnieden, 1974a); but the latter drug did not appear to affect rabbit spermatozoa (Schnieden, 1974b). Levin et al. (1981), using an objective technique of sperm motility assessment, have reported that imipramine, desipramine and nortriptyline in micromolar concentrations can decrease the motility of human spermatozoa in vitro. 
A dramatic effect was seen when three recently developed antidepressant drugs were studied (Spencer, 1977). Mianserin and viloxazine appeared to be completely without effect on hamster spermatozoa, but nomifensine significantly decreased sperm motility and whiplash motility in epididymal sperm suspensions and in the egg-containing droplets. Whilst the proportion of acrosome-reacted spermatozoa was unaffected, egg penetration in vitro was virtually completely inhibited. However, subsequent experiments indicated that this effect was probably due to the maleate moiety of the original nomifensine hydrogen maleate salt used since maleic acid acted like the latter whilst nomifensine hydrochloride was inactive. In an in-vitro system, care is obviously required when selecting a compound to study. It is suggested that Kalla \& Bansal's (1973) report that trimipramine maleate inhibited human sperm motility may be due to the maleate moiety. In the present study, maleate appeared to decrease whiplash motility in hamster spermatozoa but the acrosome reaction appeared unaffected. Since whiplash motility may provide a motive force to drive the spermatozoon through the zona pellucida (Fraser, 1981), it would be interesting to see whether maleate-treated spermatozoa would penetrate zona-free eggs.

Relatively high concentrations of maleate have been reported to decrease the motility and metabolism of ejaculated bull spermatozoa (Lardy \& Philips, 1943a, b). Various maleimides have been reported to have inhibitory effects on human and rabbit spermatozoa, possibly by a mechanism involving membrane sulphydryl groups (Reyes, Mercado \& Rosado, 1976; Mercado, Carvajal, Reyes \& Rosado, 1976; Reyes, Mercado, Goicoechea \& Rosado, 1976).

The concentrations of tricyclic antidepressant that decreased sperm motility in vitro (this study and others cited) are relatively high. However, therapeutic use of such compounds can result in plasma concentrations of up to about $1 \mathrm{~mol} / \mathrm{l}$ (Bickel, 1975). There is evidence that weakly basic drugs, such as methadone, can enter the semen via the weakly acidic prostatic fluid (Swanson, Gordon, Lynn \& Gerber, 1978). Tricyclic antidepressants have $\mathrm{pK}_{\mathrm{a}}$ values of 9-10 (Bowman \& Rand, 1980). Whilst there appear to be no reports in the literature that these compounds can be concentrated in the semen, such studies would be of value in view of the findings that higher concentrations can adversely affect spermatozoa. There is also the question of whether a drug administered to the female could reach sufficient concentration in the fluids of her reproductive tract to affect sperm function.

In view of the widespread use of antidepressant drugs, previous reports of effects on sperm motility and the findings in this study on desipramine and clomipramine, further investigation of the effects of this group of compounds on sperm motility appears warranted. Such studies should use an objective method of motility assessment.

This study was supported by a SRC CASE award in conjunction with Ciba-Geigy under the auspices of Dr G. Beaumont.

\section{References}

Anderson, R.A., Reddy, J.M. \& Zaneveld, L.J.D. (1980) Prevention of in vitro fertilizing capacity of mouse spermatozoa by ethanol. $J$. Androl. 1, 81-82, Abstr.

Austin, C.R. (1956) Ovulation, fertilization and early cleavage in the hamster (Mesocricetus auratus). J. $R$. microsc. Soc. 75, 141-154.

Austin, C.R. \& Smiles, J. (1948) Phase-contrast microscopy in the study of fertilization and early development of the rat egg. J. R. microsc. Soc. 68, 13-19.

Barnes, T.R.E., Bamber, R.W.K. \& Watson, J.P. (1979) Psychotropic drugs and sexual behaviour. $\mathrm{Br} . \mathrm{J}$. Hosp. Med. 21, 594-600.

Bavister, B.D. (1971) A study of in-vitro fertilization and capacitation in the hamster. Ph.D. thesis, Cambridge University.
Beaumont, G. (1979) Sexual side-effects of psychotropic drugs. Br. J. clin. Pract. Suppl. 4, 45-47.

Bickel, M.H. (1975) Poisoning by tricyclic antidepressant drugs. Int. J. clin. Pharmac. 11, 145176.

Bleau, G., Vandenheuvel, W.J.A., Andersen, O.F. \& Gwatkin, R.B.L. (1975) Demosteryl sulphate of hamster spermatozoa, a potent inhibitor of capacitation in vitro. J. Reprod. Fert. 43, 175-178.

Bowman, W.C. \& Rand, R.J. (1980) Textbook of Pharmacology, p. 40.4. Blackwell Scientific Publications, Oxford.

Cash, M.K.M. \& Rogers, B.J. (1981) The effect of alcohol on fertilization by human and hamster spermatozoa. Biol. Reprod. 24, Suppl. 1, 139A, Abstr. 233. 
Fraser, L.R. (1981) Dibutyryl cyclic AMP decreases capacitation time in vitro in mouse spermatozoa. $J$. Reprod. Fert. 62, 63-72.

Kalla, N.R. \& Bansal, M.P. (1973) Effect of trimipramine (Surmontil) on rat spermatogenesis. Ind. J. exp. Biol. 11, 444-445.

Lardy, H.A. \& Philips, P.H. (1943a) Inhibition of sperm respiration and reversibility of the effects of metabolic inhibitors. J. biol. Chem. 148, 333341.

Lardy, H.A. \& Philips, P.H. (1943b) Inhibition of sperm glycolysis and reversibility of the effects of metabolic inhibitors. J. biol. Chem. 148, 343-347.

Levin, R.M., Amsterdam, J.D., Winokur, A. \& Wein, A.J. (1981) Effects of psychoactive drugs on human sperm motility. Fert. Steril. 36, 503-506.

Mercado, E., Carvajal, G., Reyes, A. \& Rosado, A. (1976) Sulphydryl groups on the spermatozoa membrane. A study with a new fluorescent probe for SH groups. Biol. Reprod. 14, 632-640.

Millar, J.G.B. (1979) Drug-induced impotence. Practitioner 223, 634-639.

Reyes, A., Mercado, E. \& Rosado, A. (1976) Inhibition of capacitation and of the fertilizing capacity of rabbit spermatozoa by blocking membrane sulphydryl groups. In Recent Advances in Human Reproduction, pp. 322-324. Ed. A. C. Da Paz. Excerpta Medica (Int. Congr. Ser. 370), Amsterdam.

Reyes, A., Mercado, E., Goicoechea, B. \& Rosado, A. (1976) Participation of membrane sulphydryl groups in the epididymal maturation of human and rabbit spermatozoa. Fert. Steril. 31, 1452-1458.

Scheirer, C.J., Ray, W.S. \& Hare, N. (1976) The analysis of ranked data from completely randomized factorial designs. Biometrics 32, 429-434.

Schnieden, H. (1974a) Effect of psychoactive drugs on the motility of human spermatozoa. Int. Res. Commun. Ser.: Pharmacology, Psychiatry and Clinical Psychology; Reproduction, Obstetrics and Gynaecology 2, 1322.
Schnieden, H. (1974b) The effect of some psychoactive drugs and metallic salts on the motility of rabbit spermatozoa. Int. Res. Commun. Ser.: Pharmacology, Reproduction, Obstetrics and Gynaecology 2, 1507.

Schnieden, H. (1979) The effects of psychotrophic drugs on male reproductive function. Br. J. clin. Pract., Suppl. 4, 35-40.

Sessions, J.T., Fried, F.A., Blasco, J.M. \& Hall, J.L. (1981) Deficient fertilization by sperm from patients with inflammatory bowel disease (IBD) treated with sulphasalazine (SAS). Gastroenterology 80, 1281, Abstr.

Spencer, P.S.J. (1977) Review of the pharmacology of existing antidepressants. Br. J. clin. Pharmac. 4, (Suppl. 2), 57S-68S.

Stein, D.M. (1979) Development of a method for in-vitro fertilization of golden hamster eggs and its use to assess the effects of $\alpha$-chlorohydrin on spermatozoa. M.Sc. thesis, University of Manchester.

Stein, D.M. \& Schnieden, H. (1980) In vitro fertilization of hamster eggs as a test system for drug effects on spermatozoa-lack of effect of clomipramine. Postgrad. med. J. 56 (Suppl. 1), 58-64.

Swanson, B.N., Gordon, W.P., Lynn, R.K. \& Gerber, N. (1978) Seminal excretion, vaginal absorption, distribution and whole blood kinetics of d-methadone in the rabbit. J. Pharmac. exp. Ther. 206, 507-514.

Talbot, P. \& Franklin, L.E. (1976) Morphology and kinetics of the hamster sperm acrosome reaction. $J$. exp. Zool. 198, 163-176.

Tsunoda, Y. \& Chang, M.C. (1976) Fertilizing ability in vivo and in vitro of spermatozoa of rats and mice treated with $\alpha$-chlorohydrin. J. Reprod. Fert. 46, 401406.

Yanagimachi, R. (1970) The movement of golden hamster spermatozoa before and after capacitation. J. Reprod. Fert. 23, 193-196.

Yanagimachi, R. \& Chang, M.C. (1964) In vitro fertilization of golden hamster ova. J. exp. Zool. 156, 361376. 